\title{
A POLÍTICA DE ASSISTÊNCIA ESTUDANTIL EM UMA UNIVERSIDADE PÚBLICA: A PERSPECTIVA ESTUDANTIL
}

\author{
Adrian Alvarez Estrada ${ }^{1}$ \\ Andressa Radaelli ${ }^{2}$
}

\begin{abstract}
RESUMO: Este trabalho apresenta alguns dos resultados da pesquisa realizada junto aos estudantes atendidos pelo Programa Nacional de Assistência Estudantil (PNAES) em uma Instituição Federal de Educação Superior (IFES) criada no contexto do Programa de Apoio a Planos de Reestruturação e Expansão das Universidades Federais (REUNI). Para tanto, levamos por base a experiência, ainda que em fase inicial da Universidade Federal da Fronteira Sul (UFFS), criada em 15 de setembro de 2009. O estudo tem como objetivo analisar a política de assistência estudantil na perspectiva dos estudantes assistidos por ela. O estudo avalia se esta política vem atendendo satisfatoriamente à demanda dos estudantes em situação de vulnerabilidade econômica. Foram entrevistados 192 estudantes de diversos cursos de graduação do Campus de Realeza. Os dados apresentados nos possibilitam compreender que a expansão do acesso não é somente garantir o ingresso na universidade, é necessário também gerar condições de permanência durante a vida acadêmica. Os resultados da pesquisa indicam que das ações desenvolvidas nesse sentido, prevalecem programas que ofertam bolsas ou auxílios financeiros para subsidiar os gastos com moradia, alimentação e transporte e que para estes estudantes, esse tipo de iniciativa é essencial para permanência na universidade.
\end{abstract}

PALAVRAS-CHAVE: Acesso; Permanência; Educação Superior.

\section{Introdução}

A ampliação das políticas de acesso bem como a política de assistência estudantil objetiva a igualdade de oportunidades para os estudantes, de forma a promover a efetiva permanência (REUNI, 2007). Portanto, democratizar a educação superior, além do seu princípio fundamental que é garantia de acesso somado à qualidade, deve acima de tudo possibilitar a permanência dos que nela ingressam.

A assistência estudantil é fundamental para que muitos estudantes tenham condições de permanecer na universidade e concluir um curso superior. É importante pontuar que historicamente as ações voltadas à assistência estudantil foram desenvolvidas a partir das constantes lutas e mobilizações pela comunidade acadêmica e se apresentam de forma fragmentada e descontínua, marcada por avanços e retrocessos. De acordo com Vasconcelos (2010, p. 405) essa conquista,

Foi fruto de esforços coletivos de dirigentes, docentes e discentes e representou a consolidação de uma luta histórica em torno da assistência estudantil enquanto um direito social voltado para igualdade de oportunidades aos estudantes do ensino superior.

\footnotetext{
1 Doutor em Educação pela USP; Professor do Programa de Pós-Graduação em Educação da Universidade Estadual do Oeste do Paraná.

${ }^{2}$ Mestre em Educação pela Universidade Estadual do Oeste do Paraná.
} 
Nesse sentido, a importância de existir ações de apoio aos estudantes é inegável, levando em consideração que uma efetiva política de assistência estudantil compreende ações que vão desde condições de acesso aos instrumentos necessários à formação profissional até a geração de recursos mínimos para a sobrevivência do estudante.

Pensar em assistência estudantil, para FONAPRACE (2000), vai além de restaurantes universitários, moradia estudantil ou recursos financeiros. Ela deve ser ampliada de forma a democratizar o acesso e garantir uma universidade que, de fato, seja pública, gratuita e comprometida com a permanência de qualidade na educação superior.

\section{A Assistência Estudantil no Brasil}

A política de assistência estudantil, conforme FONAPRACE (2007) é um conjunto de princípios e diretrizes que norteiam a implantação de ações para garantir o acesso, a permanência e a conclusão de curso dos estudantes das IFES, na perspectiva de inclusão social, formação ampliada, produção de conhecimento, melhoria do desempenho acadêmico e da qualidade de vida, ou seja, deve ser considerada como uma política que vem subsidiar a expansão do acesso do estudante em situação econômica desfavorável.

Com o objetivo de dar consistência e respaldo para a implementação de políticas voltadas para a assistência estudantil, o FONAPRACE realizou um estudo sobre o Perfil Socioeconômico e Cultural dos Estudantes de Graduação das IFES Brasileiras no período de 1997 e 2004, onde mapeou a realidade nacional das universidades federais diagnosticando a situação dos estudantes matriculados. O resultado da pesquisa permitiu apresentar à ANDIFES a proposta de um Plano Nacional de Assistência Estudantil (FONAPRACE, 2011).

Assim, foi instituído conforme Brasil (2007a) o Plano Nacional de Assistência Estudantil, aprovado pela Portaria Normativa no 39 de 12 de dezembro de 2007, e adotado em 2008 a partir do repasse de verbas diretamente ao orçamento das instituições. A promulgação da regulamentação do PNAES representa um marco histórico e de importância fundamental para a assistência estudantil.

Essa Portaria Normativa foi substituída pelo Decreto 7.234 de 19 de julho de 2010. Nesse decreto, o Art. $1^{\circ}$ trata da finalidade de ampliar as condições de permanência dos jovens na educação superior pública federal. No que versa Brasil (2010) em seu Art. $2^{\circ}$ são objetivos do PNAES: 
I - democratizar as condições de permanência dos jovens na educação superior pública federal; II - minimizar os efeitos das desigualdades sociais e regionais na permanência e conclusão da educação superior; III - reduzir as taxas de retenção e evasão; e IV - contribuir para a promoção da inclusão social pela educação.

Ainda de acordo com Brasil (2010) Art. 3º parágrafo primeiro, o plano estabelece como ações de assistência estudantil iniciativas desenvolvidas nas seguintes áreas:

I - moradia estudantil; II - alimentação; III - transporte; IV - assistência à saúde; V - inclusão digital; VI - cultura; VII - esporte; VIII - creche; IX apoio pedagógico, e X - acesso, participação e aprendizagem de estudantes com deficiência, transtornos globais do desenvolvimento e altas habilidades e superdotação.

Conforme prevê Brasil (2010) no Art. 3º "deverá ser implementado de forma articulada com as atividades de ensino, pesquisa e extensão, visando o atendimento de estudantes regularmente matriculados em cursos de graduação presencial das IFES”. Continua no parágrafo $2^{\circ}$ "caberá à instituição federal de ensino superior definir os critérios e a metodologia de seleção dos alunos de graduação a serem beneficiados”, isso dá suporte ao ideal de que as universidades federais são dotadas de autonomia e que compete a elas a implantação das ações com possibilidades de adequação à sua realidade.

O número de benefícios e valores de recursos investidos no PNAES demonstra o crescimento nos recursos destinados à assistência estudantil. Como política de governo, o PNAES foi posto em prática, logo a partir do mês de janeiro de 2008, com descentralização de recursos. Segundo dados disponibilizados no site do MEC, em 2008, a rubrica destinada para a assistência estudantil nas IFES foi de aproximadamente R\$ 102 milhões, em 2009 o investimento chegou à quase R\$ 200 milhões, em 2010 o valor aproximado de R \$ 306 milhões, em 2011 o valor investido foi de R $\$$ quase 400 milhões; para 2012 o investimento chegou a cerca de $\mathrm{R} \$ 503$ milhões, para o ano de 2013 a previsão do repasse é de mais de $\mathrm{R} \$ 603$ milhões.

O número de benefícios em 2008 foram mais de 198 mil; em 2009 com o investimento de quase $\mathrm{R} \$ 200$ milhões, o número de benefícios foi de 408,5 milhões; em 2010 atingiu o número de 734.260 mil benefícios; em 2011 o valor investido foi de $\mathrm{R} \$$ quase 400 milhões com mais de 1 milhão de benefícios e para 2012 o investimento chegou a cerca de $\mathrm{R} \$ 503$ milhões.

Assim, a partir dos elementos teóricos discutidos e nos aspectos apontados sobre o PNAES realizaremos a seguir uma análise da política de assistência estudantil desenvolvida 
na Universidade Federal da Fronteira Sul (UFFS), na tentativa de compreender como a instituição, a partir do contexto nacional, concebe e organiza seus programas de assistência estudantil. 


\section{A Instituição em estudo e sua Política de Assistência Estudantil}

O objetivo desta seção é demonstrar como uma instituição federal organiza suas ações em relação à assistência estudantil e como estas são percebidas pelos atores envolvidos. A instituição de que tratamos neste estudo é a Universidade Federal da Fronteira Sul (UFFS) que emergiu no contexto do REUNI ${ }^{3}$. A UFFS está localizada geograficamente nos municípios da Mesorregião Fronteira Mercosul - Sudoeste do Paraná, Oeste de Santa Catarina e Noroeste do Rio Grande do Sul. Constituída em 2009, emerge com o intuito de contribuir para a formação humana crítica e inclusão social. Possui cinco campi, sendo: Chapecó (SC), Erechim e Cerro Largo (RG) e Realeza e Laranjeiras do Sul (PR). Esse estudo foi realizado apenas no Campus Realeza.

O Campus Realeza está localizado na Região Sudoeste Paranaense, que engloba 43 municípios divididos em quatro microrregiões. Com uma população, segundo Brasil (2007b), de aproximadamente 587.496 habitantes, distribuídos nos municípios que integram a dinâmica social, política e econômica da região. Os cursos ofertados no Campus Realeza são Ciências Naturais, Letras: Português/Espanhol, Nutrição, Medicina Veterinária, Química, Física e Ciências Biológicas. Dado esse panorama, nessa seção descreveremos a atual política de assistência estudantil desenvolvida pela UFFS.

As ações institucionais de assistência estudantil na UFFS (composta pelos programas de auxílio e bolsas financeiras) seguem as diretrizes estabelecidas em regulamento próprio, bem como o Decreto no 7.234 de 19 de Julho de 2010, que dispõe sobre o PNAES e o Decreto 7.416, de 30 de dezembro de 2010, que regulamenta a concessão de bolsas para desenvolvimento atividades de ensino e extensão universitária. Os programas caracterizam-se principalmente pela oferta de auxílios e bolsas, na forma de benefícios financeiros.

Está inserida sob a responsabilidade da Secretaria Especial de Assuntos Estudantis (SEAE), que desenvolve ações nas diversas áreas de assistência estudantil e vivência universitária, atendendo a população discente em diversas facetas de sua trajetória acadêmica, auxiliando na permanência e formação. Nos campi sua atuação se dá por meio do Setor de Assuntos Estudantis (SAEs), responsável pelo planejamento, execução e acompanhamento de programas de benefícios financeiros (bolsas e auxílios) (UFFS, 2010).

O SAE realiza análises socioeconômicas para concessão de benefícios e

\footnotetext{
${ }^{3}$ Instituído pelo decreto 6.096 de 24 de abril de 2007, tem por objetivo ampliar o acesso à Educação Superior, por meio do processo de criação, interiorização de novas IFES e abertura de novas vagas. O REUNI, em seu processo d e expansão proporcionou a criação de novos campi e de novas IFES, entre as quais a UFFS.
} 
acompanhamento aos estudantes, e a partir dos critérios de elegibilidade gera o Índice de Vulnerabilidade Socioeconômico (IVS). A noção de vulnerabilidade vem sendo utilizada como sinônimo de "risco social", "fragilização", "precariedade". No âmbito da UFFS, entende-se por Vulnerabilidade Socioeconômica conforme Art. $9^{\circ}$ CONSUNI (2011, p.03),

Um conjunto de incertezas, inseguranças e riscos enfrentados quanto à fragilização de vínculos familiares e o acesso e atendimento às necessidades básicas de bem-estar social, que envolvem condições habitacionais, sanitárias, educacionais, trabalho, renda, bens de consumo.

Além da análise socioeconômica, para que os alunos possam participar dos editais que tratam dos auxílios e bolsas da assistência estudantil, é necessário que tenham cadastro no SAEA e entreguem a documentação necessária. A análise socioeconômica destina-se aos estudantes regularmente matriculados e frequentando as aulas em curso de graduação presencial da UFFS. Essa análise tem como objetivo realizar diagnóstico da situação socioeconômica dos estudantes da instituição, gerando a partir desses dados o IVS para cada estudante, sendo classificados os estudantes com IVS no valor de até um salário mínimo e meio, de acordo com o valor do salário mínimo nacional em vigência, conforme UFFS (2010).

A seguir trataremos dos programas de bolsa e auxílios financeiros (bolsa permanência, bolsa esporte, auxílio alimentação, transporte e moradia), que compõe a política institucional de assistência estudantil desenvolvidos no Campus Realeza.

\section{Bolsa Permanência}

O programa de Bolsa Permanência tem como objetivo propiciar ao estudante em situação de vulnerabilidade socioeconômica, condições para que ele possa responder às demandas de sua formação universitária. O perfil socioeconômico do estudante é verificado nos campi da instituição a partir do processo de análise socioeconômica (UFFS, 2012c).

Os estudantes podem acumular ${ }^{4}$ a bolsa permanência com um auxílio (alimentação, transporte ou moradia). Para a seleção será considerada a ordem de classificação do IVS

\footnotetext{
${ }^{4}$ Conforme Instrução Normativa n ${ }^{\circ} 002 / 2012$ que dispõe sobre o acúmulo de auxílio financeiro concedido pela SEAE com demais bolsas em seu Art. $4^{\circ}$ É permitido que os estudantes contemplados com auxílios socioeconômicos (Auxílios Alimentação, Moradia e Transporte)(Bolsa Permanência) possam acumular seus auxílios com até 1 (uma) bolsa acadêmica. Art. $5^{\circ}$ Por bolsa acadêmica entende-se toda modalidade de bolsa que demande horas de trabalho ou produtividade. (EX.: Bolsa Esporte; Bolsa Extensão; Estágio Remunerado; PIBID; PET), conforme UFFS (2012a).
} 
dos estudantes inscritos e a disponibilidade orçamentária, e a concessão dos benefícios é efetuada em três valores ( $\mathrm{R} \$ 150, \mathrm{R} \$ 240$ e $\mathrm{R} \$ 300$ reais), de acordo com o grau de vulnerabilidade socioeconômica do estudante.

O critério de concessão da bolsa é feito por meio da análise da situação socioeconômica além do preenchimento dos seguintes requisitos: a) estar cursando, no mínimo, 12 (doze) créditos semanais no semestre; b) ter cadastro socioeconômico atualizado e na condição de classificado; c) ter aprovação por nota em no mínimo 50\% dos créditos cursados e nenhuma reprovação por frequência em qualquer disciplina do semestre anterior, em caso de ter sido beneficiário de bolsas ou auxílios (moradia, transporte ou alimentação) conforme UFFS (2012c).

O desligamento do bolsista ocorrerá em caso de ausência sem justificativas em dois eventos promovidos pelo campus (como palestras, cursos) ou nas seguintes circunstâncias: a) solicitação do próprio estudante; b) descumprimento das situações previstas no edital; c) trancamento de matrícula ou desistência de curso; d) superação da situação de vulnerabilidade socioeconômica e/ou alteração da situação de alimentação; e) qualquer irregularidade, inveracidade e/ou omissão de informações constatadas durante o período de vigência do benefício. Caso isso ocorra, a substituição por outro estudante será realizada de acordo com o IVS e previsão orçamentária, desde que o candidato à substituição preencha os pré-requisitos do edital (UFFS, 2012c).

\section{Auxílio Alimentação, Transporte e Moradia}

Tendo em vista o decreto do PNAES, o auxílio alimentação tem como objetivo propiciar auxílio financeiro aos estudantes de graduação em situação de vulnerabilidade socioeconômica. Para ter direito ao auxílio alimentação poderão se candidatar os estudantes da UFFS procedentes de outro município ou distrito/interior da cidade onde o campus está instalado, antes do ingresso na universidade, e residir atualmente no município em que estuda; frequentar curso integral e/ou estar participando em projetos de ensino, pesquisa ou extensão. Esta situação deve ser informada e comprovada no cadastro socioeconômico. O auxílio alimentação no ano de 2012 era no valor de $\mathrm{R} \$ 80,00$.

O auxílio moradia consiste na concessão de valor financeiro a estudantes oriundos de outros municípios ou distrito/interior da cidade onde o campus está instalado e residir em imóvel alugado ou pensionato no município em que estuda. O valor é de R \$ 120,00 e nos critérios adotados pelo SAE, é destinado para subsidiar suas despesas com moradia 
(aluguel, água, luz, gás) (UFFS, 2012b).

O auxilio transporte, no valor de $\mathrm{R} \$ 50,00$, é destinado aos estudantes que utilizam transporte coletivo ou locado no seu deslocamento da residência para a universidade e viceversa. Esta situação deverá ser comprovada com o cadastro socioeconômico (UFFS, 2012b).

O critério de concessão da bolsa é feito por meio da análise da situação socioeconômica e de desempenho escolar do aluno além do preenchimento dos seguintes requisitos: a) estar cursando, no mínimo, 12 (doze) créditos semanais no semestre letivo; b) ter cadastro socioeconômico atualizado e na condição de classificado, conforme estabelece a Resolução 001/2011 - CONSUNI/CE; c) ter aprovação por nota em no mínimo 50\% dos créditos cursados e nenhuma reprovação por frequência em qualquer disciplina do semestre anterior, em caso de ter sido beneficiário de bolsas ou auxílios (moradia, transporte ou alimentação) da Diretoria de Assuntos Estudantis conforme UFFS (2012b).

O estudante, conforme trata UFFS (2012c) será desligado nas seguintes circunstâncias: a) solicitação do próprio estudante; b) descumprimento das situações previstas no edital; c) trancamento de matrícula ou desistência de curso; d) superação da situação de vulnerabilidade socioeconômica; e) qualquer irregularidade, inveracidade e/ou omissão de informações constatadas durante o período de vigência do benefício. Caso isso ocorra, a substituição por outro estudante será realizada de acordo com o IVS e previsão orçamentária, desde que o candidato à substituição preencha os pré-requisitos do edital (UFFS, 2012b).

\section{Bolsa Esporte}

Observando os princípios e objetivos do PNAES, dentre eles a prática e intercâmbio esportivos voltados ao desenvolvimento integral do estudante, a UFFS oferece auxílio financeiro para promoção do esporte. Esse programa visa promover a integração acadêmica a partir da inserção do estudante de graduação em atividades de incentivo à prática esportiva, contribuindo para a formação universitária (UFFS, 2012d).

O bolsista deverá ainda, apresentar ao SAE um cronograma de atividades propostas; organizar e coordenar equipe/participantes na modalidade em que é responsável, respondendo como atleta e capitão da modalidade. O bolsista será desligado nas seguintes situações: a) solicitação do próprio estudante; b) solicitação do SAE pelo não cumprimento das atividades previstas; c) frequência ou desempenho acadêmico 
insuficiente; d) trancamento de matrícula ou desistência de curso; e) qualquer irregularidade verificada durante o período de vigência da bolsa (UFFS, 2012d).

\section{A assistência na perspectiva estudantil: análise dos dados}

Diante do contextualizado, entendemos que a política de assistência estudantil tem como objetivo auxiliar na permanência dos estudantes na educação superior pública a fim de que estes possam concluir sua graduação. Assim, esta seção busca identificar a percepção dos sujeitos pesquisados sobre o programa de bolsas e auxílios financeiros da UFFS, objeto da presente investigação e suas implicações para a permanência estudantil. A seguir apresentamos alguns dos dados coletados.

Os dados foram coletados utilizando questionários aplicados a 192 alunos que receberam algum benefício do programa de bolsas e auxílios financeiros da UFFS Campus Realeza, destes, 160 responderam ao questionário (83\%). Enfatizamos que este estudo restringiu a análise e percepção dos estudantes beneficiados no ano de 2012, assim, as informações coletadas dizem respeito à situação dos entrevistados nesse período. Os dados compuseram o cenário para a análise das suas condições de permanência, bem como das ações institucionais adotadas quanto à assistência e o atendimento de suas demandas.

Da população que respondeu ao nosso estudo verificamos que $82 \%$ são do sexo feminino e $18 \%$ do sexo masculino. Esse dado pode estar relacionado ao crescimento da participação das mulheres no mercado de trabalho e a consequente busca por formação. Verificamos ainda que 38\% estão matriculados no curso de Licenciatura em Ciências: Biologia, Física e Química, 28\% estão matriculados no curso de Nutrição, 18\% no curso de Medicina Veterinária e 16\% no curso de Licenciatura em Letras: Português/Espanhol.

Deste total $46 \%$ da população atendida está matriculada em cursos integrais sendo 60\% do curso de Nutrição e 40\% de Medicina Veterinária. Os cursos ofertados no período noturno correspondem a 54\% da amostra de estudantes pesquisados; do total destes, 7\% estão matriculados em Licenciatura em Ciências, e 30\% em Licenciatura em Letras.

Com referência à habitação ressalta-se o predomínio de $78 \%$ de estudantes que moram no estado do Paraná, 13\% em Santa Catarina, 6\% no Rio Grande do Sul e 3\% em outros estados como Amazonas, São Paulo e Mato Grosso. Permite identificar o fluxo migratório dos alunos para ingressar na instituição. A soma dos alunos oriundos de outro estado constitui este fluxo, totalizando $22 \%$. O percentual indica que estes alunos não têm convívio familiar, correspondendo a uma demanda potencial por permanência, moradia e 
alimentação.

Coerentemente com a situação do local de residência antes do ingresso na UFFS, analisarmos onde e como os estudantes moram atualmente, verificamos que $44 \%$, residem em casa ou apartamento que divide com colegas ou amigos; $24 \%$ residem em casa ou apartamento com família (pais/irmãos/filhos); $13 \% \mathrm{em}$ casa ou apartamento com esposa/marido/ companheiro(a) / filho(s); $6 \%$ somente com mãe ou pai; $4 \%$ em casa ou apartamento, sozinho(a); 3\% em casa de parentes ou familiares; $2 \%$ em pensionato; $1 \% \mathrm{em}$ quarto ou cômodo alugado, sozinho(a) e 3\% em outros que de acordo com respostas incluem em somente com filhos; cônjuge, mãe e irmãos; com irmã e sobrinhos ou em casa cedida.

Quanto à moradia, relacionando com os dados referentes à pesquisa realizada pelo FORNAPRACE em 2000, a qual apontou que 25,3\% dos estudantes residem fora do seu contexto familiar, em casa de amigos, casa de familiares, casa mantida pela família, pensão, hotel, pensionato, e/ou república. Apenas 2,5\% moram em residência universitária, com destaque para as regiões Norte com apenas 0,63\%, o menor percentual, e Sul com 3,46\%, o maior percentual (FONAPRACE, 2011). Verificamos que a média de estudantes que se encontram nessa condição é superior no Campus Realeza (51\%). Conforme enfatiza Zago (2006, p. 233),

Provenientes de outras cidades ou estados, pouco mais da metade tem suas despesas acrescida pelo fato de não morar com a família. Nesses casos, residem na casa do estudante universitário (quando há vaga), ou com parente, ou ainda, dividem casa ou apartamento com colegas.

No que se refere ao transporte, com as informações coletadas podemos verificar o principal meio de transporte utilizado pelos estudantes para chegar ao Campus Realeza, onde $43 \%$ que utilizam transporte escolar (van/ônibus), 41\% utilizam transporte público. Apenas 9\% deslocam-se em meio próprio de transporte (carro/moto); 3\% vão a pé, 3\% pegam carona e $1 \%$ utilizam a bicicleta.

A pesquisa realizada pelo FONAPRACE (2000) aponta que 60,60\% dos estudantes de IFES necessitam de transporte para deslocamento à Universidade. Em nosso estudo, o transporte coletivo é responsável pela locomoção de $84 \%$ dos estudantes. Tal informação é relevante quando tratamos do auxílio transporte, pois é considerável o quantitativo dos que utilizam transporte escolar como van/ônibus ou transporte público, pois esse benefício concedido é destinado ao custeio das despesas realizadas com transporte.

A partir da coleta de dados verificamos que do total de entrevistados, $45 \%$ não 
trabalha e recebe auxílios da UFFS e da família, 24\% não trabalha e só recebe auxílios da UFFS; $15 \%$ trabalha e recebe auxílios da UFFS; $7 \%$ não trabalha e os gastos são pagos somente pela família; $4 \%$ trabalha e é o único responsável pelo sustento; 3\% trabalha, recebe auxílio da UFFS e da família, 1\% trabalha e recebe auxílio financeiro da família ou de outras pessoas e 1\% trabalha e é responsável pelo sustento da família. Ou seja, no total, apenas $24 \%$ dos alunos informaram ter trabalho remunerado, seja ele formal ou informal. Tal informação está diretamente relacionada ao fato de um percentual elevado de estudantes estarem matriculados em cursos integrais, enaltecendo a necessidade da elaboração e execução continuada do atendimento às necessidades estudantis.

Com relação à renda dos estudantes entrevistados, verificamos que 52\% tem uma renda individual total de $\mathrm{R} \$ 300,00$ a $\mathrm{R} \$ 600,00 ; 32 \%$ tem a renda de até $\mathrm{R} \$ 300,00 ; 12 \%$ possuem renda individual de $\mathrm{R} \$ 600,00$ a $\mathrm{R} \$$ 800,00; 3\% recebem algum tipo de benefício governamental e apenas $1 \%$ com mais de $\mathrm{R} \$ 800,00$.

Se levarmos em consideração que um estudante pode acumular um auxílio (moradia, alimentação ou transporte) com uma bolsa (permanência ou esporte) e os valores disponibilizados pela assistência estudantil: auxílio alimentação $\mathrm{R} \$ 80,00$, auxílio moradia $\mathrm{R} \$ 120,00$, auxílio transporte $\mathrm{R} \$ 50,00$, bolsa permanência $\mathrm{R} \$ 150,00, \mathrm{R} \$ 240,00$ ou $\mathrm{R} \$$ 300,00 e bolsa esporte $\mathrm{R} \$ 360,00$, verificamos que a renda dos estudantes ficaria abaixo dos $\mathrm{R} \$ 500,00$.

Como enfatiza FONAPRACE (2011), muitos estudantes não dispõem de recursos para suprirem suas necessidades básicas e, ainda menos, as despesas típicas da vida universitária. Ele precisa de livros, equipamentos de aprendizagem prática, acesso à informação, participação em eventos acadêmicos e culturais. Assim, questionamos sobre o gasto mensal que os estudantes possuem para manter-se estudando, $32 \%$ gasta de $\mathrm{R} \$$ 300,00 a $\mathrm{R} \$ 400,00 ; 23 \%$ possui um gasto de $\mathrm{R} \$ 200,00$ a $\mathrm{R} \$ 300,00 ; 23 \%$ possui um gasto de $R \$ 400,00$ a $R \$ 500,00,13 \%$ gasta entre $R \$ 500,00$ a $R \$ 600,00$ para manutenção dos estudos e 9\% tem um gasto maior que $\mathrm{R} \$ 600,00$.

As dificuldades de permanência na universidade são muitas e devem ser considerados na definição da política de assistência. Assim, quanto aos benefícios recebidos pelos estudantes verificamos que 4\% receberam auxílio alimentação, 25\% auxílio moradia, 20\% auxílio Transporte, 5\% receberam bolsa esporte e 46\% receberam bolsa permanência. Vale ressaltar que um estudante poderia acumular uma bolsa com um auxílio.

Sobre as condições de permanecer estudando sem o recebimento do(s) auxílio(s) verificamos que $16 \%$ respondeu que seus pais poderiam custear os gastos; $4 \%$ 
responderam trabalham e podem sustentar-se com o que ganham; $29 \%$ responderam que não teriam como trabalhar e não tem outras formas de geração de renda e 51\% responderam seus pais não têm condições de manter, portanto não teriam condições de permanecer estudando.

Com relação à opinião dos estudantes sobre a assistência estudantil desenvolvida pela UFFS, verificamos que $28 \%$ a consideram importante, pois a maioria dos estudantes da universidade necessita; $48 \%$ a considera fundamental, sem ela grande parte dos estudantes não teria como se manter na universidade; $17 \%$ fundamental, desde que os recursos sejam destinados para os que realmente precisam; $6 \%$ entende que precisa melhorar em muitos aspectos, pois ainda não atende as necessidades dos estudantes e apenas $1 \%$ considera que a maioria dos alunos que recebem os auxílios conseguiria manterse sem esse benefício.

Nesse sentido, os estudantes são enfáticos em exigir políticas públicas que garantam a permanência e qualidade nos estudos, pois, com relação à forma como os estudantes enxergam a assistência estudantil para os próximos anos, a análise inicial evidência a necessidade de ampliação, pois $72 \%$ dos estudantes acreditam que precisa ser ampliada e receber mais verbas, 23\% devem ser incluídas novas formas de auxílios e 5\% devem ser estabelecidas novos requisitos para participação e recebimento.

Assim, verificamos nos dados a seguir a importância de ouvir e debater com os estudantes, quais ações precisam ser melhoradas, ampliadas ou ainda incluídas na política assistencial institucional da UFFS. Perguntamos a respeito de quais outros benefícios poderiam ser inclusos no programa institucional de assistência estudantil desenvolvido pela UFFS e como resultado obtivemos um percentual de $17 \%$ que considera a moradia estudantil como prioridade para ser disponibilizado, 23\% o estágio remunerado, $6 \%$ a assistência à saúde, 28\% consideram como necessário o restaurante universitário, 23\% consideram importante que haja recursos para livros e cópias e 3\% consideram outros, que segundo respostas atenderiam a todos os anteriores, ou seja, que todos citados acima são de extrema importância e poderiam ser disponibilizados. Entendemos assim, que a assistência estudantil, precisa abarcar ações que atendam os estudantes, que dela necessitam, em suas especificidades enquanto sujeitos em formação.

Os dados apresentados evidenciam que alguns fatores influenciam na desistência ou trancamento do curso, assim identificamos que $65 \%$ o faria por questão financeira (não ter condições de manter-se), $10 \%$ em decorrência do tempo de conclusão do curso, $3 \%$ pelo período/turno do curso, $5 \%$ por não ser o curso que desejaria seguir carreira, $2 \%$ pela 
visibilidade econômica que o curso proporciona, 10\% por não conseguir conciliar trabalho e estudo e $5 \%$ por não conseguir auxílio da assistência estudantil.

Em resumo, a efetiva democratização da educação deve vir acompanhada de medidas efetivas de assistência estudantil que auxiliem conforme ações sugeridas pelo PNAES e tenham como prioridade viabilizar a igualdade de oportunidades, além de contribuir para minimizar as situações de repetência e evasão decorrentes da insuficiência de condições financeiras.

\section{Considerações Finais}

Nas considerações de Finatti (2007) as dificuldades não se encontram somente no ingresso na universidade. A permanência é outro desafio, uma vez que os estudantes, mesmo matriculados em instituições públicas, têm gastos com transporte, alimentação, material didático entre outros. Portanto, além da ampliação do acesso, nos cabe aqui refletir sobre as atuais condições de permanência, para que este não fique somente no plano legal.

Fica claro que a UFFS não possui uma efetiva política institucional de assistência estudantil, e que apesar de estar ainda em fase de construção encontra-se avançada em alguns pontos, pois desde a implantação da instituição já possui recursos para assistência estudantil. Porém, o que encontramos são apenas ações isoladas regulamentadas por instruções, resoluções específicas ou editais prevalecendo programas que ofertam bolsas ou auxílios financeiros para subsidiar os gastos com moradia, alimentação e transporte.

Frente a essas questões, é necessária à discussão sobre a qualidade do ensino, onde compartilhamos com Paula (2009, p. 19) a ideia de que a "democratização do acesso ao ensino superior só se dará de forma satisfatória com a expansão qualificada das instituições públicas, com garantia de infraestrutura e pessoal qualificado, o que requer recursos e investimentos por parte do governo".

Verificamos que alguns possuem um maior auxílio por parte da família, o que de alguma forma gera melhoria de renda. Destacamos o fato de que muitos desses estudantes teriam uma renda muito inferior se não tivessem auxílios da assistência e dependessem única e exclusivamente da ajuda financeira dos pais, o que nos leva a premissa inicial da assistência estudantil, ainda não suficiente, porém importante para a permanência dos estudantes.

Constata-se ainda, que são muitos os desafios para a consolidação de uma política de assistência estudantil efetiva, contudo, podemos afirmar que, se o PNAES é uma política 
importante quanto à ampliação da possibilidade e geração de condições de permanência na educação superior, os dados recolhidos por esta pesquisa demonstram que, uma vez possibilitado o acesso, a permanência dos estudantes se torna fundamental a fim de que o chamado processo de democratização seja considerado efetivo.

Por fim, cabe sublinhar que as questões que se apontam em nosso estudo, assentam os limites e possibilidades no processo de luta pelos direitos dos estudantes, exigindo dos sujeitos envolvidos nesse processo um olhar crítico. Os dados refletem a necessidade de implementação de uma política baseada em uma profunda discussão, com novas perspectivas na ampliação de recursos e programas que permitam uma efetiva inserção social. 


\section{Referências Bibliográficas}

BRASIL, Portaria Normativa $N^{\circ}$ 39, de 12 de Dezembro de 2007. Institui o Programa Nacional de Assistência Estudantil - PNAES. Brasília, 2007a. Disponível em: http://portal.mec.gov.br/arquivos/pdf/portaria pnaes.pdf. Acesso em 08/02/2013.

- Ministério do Planejamento, Orçamento e Gestão. IBGE - Instituto Brasileiro de Geografia e Estatística. Anuário Estatístico do Brasil. Rio de Janeiro: 2007b.

Decreto n ${ }^{\circ}$ 7.234, de 20 de dezembro de 2010: Programa Nacional de Assistência Estudantil PNAES. Presidência da República Federativa do Brasil. Brasília, 2010. Disponível em: http://www.planalto.gov.br/ccivil 03/ Ato2007-2010/2010/Decreto/D7234.htm. Acesso em 18/07/2012.

CONSUNI. Resolução No 001/2011 - CONSUNI/CE. Estabelece regras para a realização de análise socioeconômica permanente. Chapecó. 2011. Disponível em: www.uffs.edu.br. Acesso em 10/03/2013.

FINATTI, Betty Elmer. Assistência Estudantil na Universidade Estadual de Londrina/UEL. 2007. Dissertação de Mestrado. Universidade Estadual de Londrina, Londrina.

REUNI. Reestruturação e Expansão das Universidades Federais: Diretrizes Gerais. 2007. Disponível em: portal.mec.gov.br/sesu/arquivos/pdf/diretrizesreuni.pdf. Acesso em 16/04/2013.

FONAPRACE, Fórum Nacional de Pró-reitores de Assuntos Estudantis e Comunitários. Assistência Estudantil: Uma questão de Investimento. 2000. Disponível em: http://www.unb.br/administracao/decanatos/dac/fonaprace/documentos/assist est.html. Acesso em 25/06/2012.

Plano Nacional de Assistência Estudantil - Aprovado pela ANDIFES. Brasília. 2007. Disponível em: http://www.ufpa.br/fonaprace. Acesso em 08/02/2013.

Perfil Socioeconômico e Cultural dos Estudantes de Graduação das Universidades Federais Brasileiras. Brasília - 2011.

PAULA, Maria de Fátima. As políticas de democratização: o acesso ao ensino superior do governo Lula. Revista Advir, $\mathrm{n}^{\circ}$ 23, 2009, p. 11-19. Disponível em: http://www.asduerj.org.br/index.php/publicacoes/advir. Acesso em 25/04/2013.

UFFS, Universidade Federal da Fronteira Sul. 2010. Disponível em: http://www.uffs.edu.br/. Acesso em 27/02/2013.

- Instrução Normativa no02/2012. Dispõe sobre o acúmulo de auxílio financeiro concedido pela SEAE com demais bolsas. Chapecó, 2012a. Disponível em http://www.uffs.edu.br. Acesso em 27/02/2013. 
Edital ño 042/UFFS/2012 - auxilios alimentação, moradia e transporte. Chapecó, 2012b. Disponível em: http:/ $/$ www.uffs.edu.br/index.php?option $=$ com content\&view $=$ article\&id $=553 \&$ Itemid $=$ 899. Acesso em 26/02/2013.

Universidade Federal da Fronteira Sul. Edital $n^{0}$ 043/UFFS/2012 - bolsa permanência. Chapecó, 2012c. Disponível em: http:/ / www.uffs.edu.br/index.php?option $=$ com content\&view $=$ article\&id $=553 \&$ Itemid $=$ 999. Acesso em 26/02/2013.

Universidade Federal da Fronteira Sul. Edital no 044/UFFS/2012 - bolsa esporte. Chapecó, 2012d. Disponível em: http:/ $/$ www.uffs.edu.br/index.php?option $=$ com content\&view $=$ article\&id $=553 \&$ Itemid $=$ 999. Acesso em 26/02/2013.

VASCONCELOS, Natalia Batista. Programa Nacional de Assistência Estudantil: Uma Análise da Evolução da Assistência Estudantil ao Longo da História da Educação Superior no Brasil. Revista da Católica, Uberlândia, v. 2, n. 3, p. 399-411, 2010. Disponível em: http://www.catolicaonline.com.br/revistadacatolica/artigosv2n3/29-Pos-Graduacao.pdf. Acesso em: 25/01/2012.

ZAGO, Nadir. Do acesso à permanência no ensino superior: percursos de estudantes universitários de camadas populares. Revista Brasileira de Educação, São Paulo, v. 11, n. 32, p. 226-237, maio/ago. 2006. 